\title{
Climate Change: Uncertainty for Hydropower Development in
}

Nepal

Mahesh Pathak

Abstract: There is a worldwide consensus that climate change is a real, rapidly advancing and widespread threat facing this century. This is a crucial issue in Himalayan and special in Nepal because of its possible impact on water resource, biodiversity, and consequence on economic growth of the region. The increase trend of glacial retreat and variability on temperature and participation has the direct impact on the water resource and hydropower development. Mountain regions are particularly vulnerable, both because warming trends are higher and the impacts are magnified by the extreme changes in altitude over small distances. It indicates the great variability of hydro-climatic variability in major rivers and their tributaries. Decrease runoff will have direct impact on the hydropower development, but there is uncertainty about the role of spatial variability of changing climatic scenarios and their possible impact for hydropower development in large and middle rivers. This paper presents the scenarios of climate change in Nepal in terms of hydro-climatic variability. The first part describes hydro-climatic variability and its uncertainty for hydropower development, and the second part deals with the mitigation of uncertainties.

Key words: Climate change, deglaciation, GLOF, water resources, hydrological cycle, hydropower, Himalayas, Nepal

\section{Climate Change}

$\mathrm{T}$ emperature increase is widespread over the globe, with higher than average trends in many of the world's highlands. On average the global temperature has risen by $0.74^{\circ} \mathrm{C}$ over the last hundred years (1906-2005), with more than half of this rise, $0.44^{\circ} \mathrm{C}$, in the last 25 years (McCarthy, Bajracharya and J oshi 2001). The global average surface air temperature is projected to warm 1.4 to $5.8^{\circ} \mathrm{C}$ by 2100 relative to 1990 .

Climate change observed over the past several decades is consistently associated with changes in a number of components of the hydrological cycle and hydrological systems such as: changing precipitation patterns, intensity and extremes; widespread melting of snow and ice; increasingatmospheric watervapor; increasingevaporation; and changes in soil moisture and runoff. One of the most visible impacts of climate change in the Himalayan region is the retreat of the glaciers, many at higher rates than glaciers in other mountain ranges. The permanent snowline has moved significantly higher, although the observations are too few to be able to quantify the actual loss of snow cover in the region. Continued deglaciation could have a profound impact on the water in the ten large river basins originating in the $\mathrm{HKH}$ (Hindu Kush-Himalayan) region. River discharges are likely to increase for some time due to accelerated melting, but the flow is then likely to be lower as the storage capacity of the glaciers goes down.

Hydropower is clearly among the most vulnerable areas to global warming because water resources are closely linked to climate changes. Climate projections show that potential change in precipitation and temperature brought about by climate change could affect runoff. ICIMOD (the International Center for Integrated Mountain Development) has studied the impact of projected climate change on the hydrological regime of some river basins of the Himalayan region, and shown a clear difference between the basins dominated by summer monsoon and those dominated by winter precipitation. This in turn affects the potential water utilization and the benefits of hydropower development or continuing to operate a hydropower plant.

\section{Uncertainty for Hydropower Development}

Due to the climate change, there will be certain uncertainties associated with the whole hydrologic cycle. Hydrologic cycle itself is a complex system and the climatic and hydrologic changeswill addmoreuncertaintiestoitscomplexities. Every component of the cycle, viz., evaporation, transportation, and precipitation and run off, will be affected in different magnitudes and thus, new balance in the cycle will be created, which may not be the same as present. The existing hydropower plants may not function with designed capacity, as the low flows might be decreasing.

Direct observations and proxy records indicate that historical and recent changes in climate in many mountain regions of the world are at least comparable with, and locally may be greater than, those observed in the adjacent lowlands. Regional and local physiographic differences of Nepal further increase the natural variability-on interannual to decadal time-scales-in all components of the hydrological cycle. Thus, mountain regions are particularly vulnerable, both because warming trends are higher and the impacts are magnified by the extreme changes in altitude over small distances. This indicates the higher uncertainty of the scenario of climate change in mountain areas of Nepal. Mountain systems are particularly sensitive to climate changes. Small changes in climate can produce significant regional or larger-scale effects. In particular, marginal environments are under high stress. Small changes in water 
availability, floods, drought, landslides and late frosts can have drastic effects on hydropower development.

The most critical impacts of climate change in Nepal can be expected to be on its water resources, particularly glacial lakes, and its hydropower generation. Water supply infrastructure and facilities are at risk from increased flooding, landslides, sedimentation and more intense precipitation events (particularly during the monsoon) expected to result from climate change. Greater unreliability of dry season flows, in particular, poses potentially serious risks to water supplies in the lean season. Hydroelectric plants are highly dependent on predictable runoff patterns. Therefore, increased climate variability, threatens the potential for hydropower generation. This uncertainty should be investigated to analyze the economic benefit of designing hydropower plants with the possibility of future lowered capacity.

Understanding climatic variability is crucial for designing hydropower plants and to mitigate with the changing climatic scenarios in Nepal. This situation also raises questions regarding the established hydropower potentiality of Nepal. Now it is necessary to identify the hydropower power potentiality considering the changing climatic scenarios. Changing climatic scenarios for hydropower development need to understand in terms of increase temperature variability, glacial retreat and river flow discharge.

\section{Increased Temperature}

Temperature observations from 1977-1994 show that differences are most pronounced during the dry winter season, and least during the height of the monsoon.

There is also significantly regional and local variability of increase temperature, with greater warming at higher elevations in the northern part of the country than at lower elevations in the south (Shreshtha et al 1999). Increase

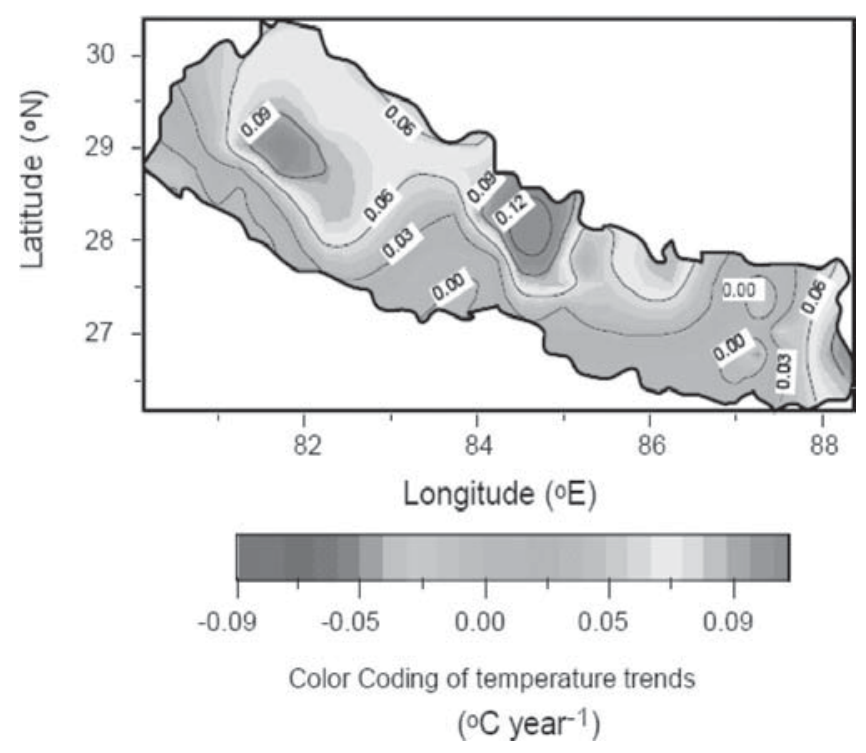

Figure 1. Spatial Distribution of Annual Average Maximum Temperature Trends in Nepal 1977 to 1994 (Shreshtha et al 1999, quoted in Thomas and Rai 2005). temperature directly affects, glacial retreat, precipitation and evaporation and varies at regional and local scale. Increase temperature at high altitude in and low altitude may have the different consequence in snow feed and other rivers. Increase temperature indicates the increase runoff in the snow fed river. On the other hand, increase temperature in middle hill region increase the evaporation in dry season and decrease the dry season water flow in the middle and small scale rivers.

\section{Glacier Retreat and GOLF}

Glaciers 'mother' several rivers and streams with melt runoff. A significant portion of the low flow contribution of Himalayan rivers during the dry season is from snow and glaciers melt in the Himalayan region. It is pointed that the accelerated melting of glaciers will cause an increase in river levels over the next few decades, initially leading to higher incidence of flooding and land-slides. But, in the longerterm, as the volume of ice available for melting diminishes, a reduction in glacial runoff and river flows can be expected.

Continued glacier retreat can also reduce dry season flows fed by glacier melt, while there is moderate confidence across climate models that the monsoon might intensify under climate change. This contributes to enhanced variability of river flows. Potential intensification of monsoons combined with enhancement of GLOF risks also contributes to enhanced risk of flooding and landslides which can have serious impact on hydropower generation, on slope stability and on hazards relating to avalanches and glacier lakes. Extreme events such as glacial lake outburst floods (GLOFs) have the largest potential affect on water resources project because the force of a GLOF is often capable of destroying all hydropower infrastructures in a very short period. This happened in the Dig Tsho GLOF in 1985 that completely swept away the Namche Hydropower Plant in the Khumbu region (Thomas and Rai 2005).

These climate concerns can span a variety of time scales, ranging from seasonal to inter-annual variability. In the coming years, hydropower planners may also need to incorporatemeasurestoadaptto climatechange, particularly in Nepal where GLOF events occur on a massive scale.

\section{Variability on River Runoff}

Two factors will contribute to increased variability of river runoff: (a) glacier retreat and (b) changes in timing and intensity of precipitation. Runoff will initially increase as glaciers melt then later decrease as deglaciation progresses. In addition, decreased winter snowfall means less precipitation will be stored on the glaciers, which in turn will decrease the spring and summer runoff. Studies on climate variability in Southwest Asia show that decreased winter snowfall does indeed decrease the spring/ summer runoff, and it has caused severe droughts in Iran and Pakistan in areas that depend on water from mountain sources (Subbiah 2001). Water 


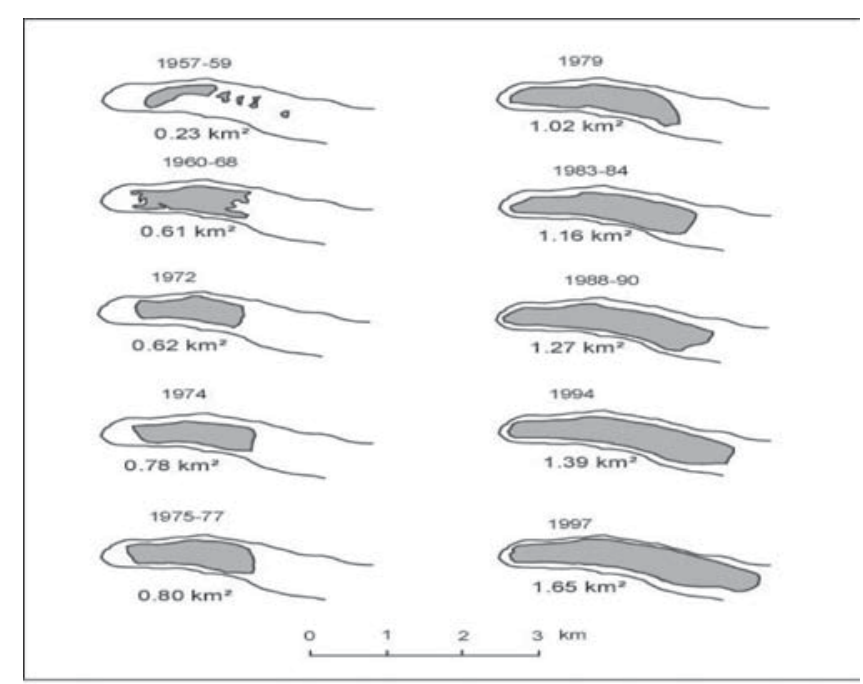

Figure 2. Growth of Tsho Rolpa from the Late 1950s to 1997 (Mool et al 2002).

availability from surface water sources or shallow groundwater wells depends on the seasonality and inter-annual variability of stream flow, and a secured water supply is determined by seasonal low flows. In snow- dominated basins, higher temperatures lead to reduced stream flow and thus decreased water supply in summer.

Many of Nepal's rivers are fed by runoff from the over three thousand glaciers scattered throughout the country. Some of the most prominent rivers in Nepal have average annual flows of $1,500 \mathrm{~m}^{3} / \mathrm{s}$, including the Koshi, Gandaki and Karnali. The most severe projections for Nepal show that runoff could reduce by 14 percent. This would reduce the electricity generation of existing plants. This runoff decrease will affect Nepal's economically feasible hydropower potential as well as existing hydropower plants (Agrawala et al 2003).

Climate change has a number of implications for stream flow variability in Nepal. Shakya (2003) points out that 90\% of debris volume in Nepal is transported by approximately $20 \%$ of rainfall. With the intense rainfall projected for the monsoon season, sedimentation is another factor that may shorten the operating life of a hydropower plant. There has also been an observed increasing trend in the number of flooding days. On the other hand, there might be significant declines in the dependability of dry season flows in certain rivers, which is quite critical for both water and energy supply.

More than 6,00o rivers and rivulets flow through Nepal. A comprehensive analysis of trends in river flow is necessary to understand the runoff variability in the large and middle rivers. Among thelarge rivers, Karnali and Sapta Koshi show decreasing trends although the records for Sapta Koshi are quite short. In contrast, the Narayani, another large river, displays an increasing trend. Southern rivers do not show any trend. All of the three snow-fed rivers examined showed declining trends in discharge.

Hydropower projects in Nepal are of the 'run-of-river' (RoR) type and are more vulnerable to stream flowvariability.
Adequate consideration of the changes and characteristics of the variability of stream flow and associated events such as flooding and precipitation risks require in water resource and hydropower planning.

\section{Mitigation with Uncertainty}

Issue of theuncertainty of hydropower developmentin Nepal are because to the variability of hydro-climatic scenario at temporal and spatial scale. Understanding the scenario at temporal and spatial scale and its consideration in the designing phase will be the best way to mitigate the impact

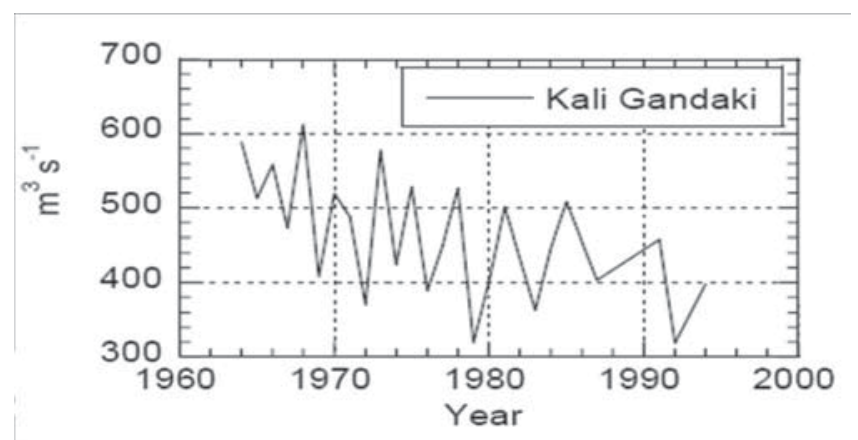

Figure 3. Water Discharge in Kali Gandaki River (Thomas and Rai 2005).

of climate change in hydropower development. Uncertainty for hydropower development caused by climate change can be minimized by understanding watershed concept of analysis, use of advance technique to update real time climatic data and public access to these data by developing a data sharing platforms.

A watershedistheareaofland thatdrainswater, sediment and dissolved materials to a common outletalongsome point in the stream channel. Many ecological, environmental and human processes occur within a watershed. The watershed provides a powerful study and management unit which integrates ecological, geographical, geological, and cultural aspectsand establishestheirconnection atlocal, regional and global connection. Watershed concept has been emerging as important spatial unit of analysis to understand the impact of climate change. Watershed approach provides holistic approach to understand the regional variability of climate change. Study of major rivers and their tributaries from the watershed perspectives helps to disaggregate the hydroclimatic data at themicro scale. Understating of theimpact of climate change is very crucial for designing the micro, small and middle hydropower projects. The watershed concept is the best way to understand the environmental and ecological degradation at local scale (Pathak 2008). Understanding of the uncertainty of hydro-climatic variability at national and regional scale are not enough to understand the possible impact of climate change for micro and small and medium scale hydropower project. There is necessary to integrate hydro-climatic data at watershed scale.

Anothercauseofuncertainty of hydropower development is regional and local variation in the changing climatic 
scenarios. To understand this requires higher temporal and spatial resolution hydro-climatic information. Recent data represent the national and regional scenarios and rarely address local variability. Ground based observations will be quite difficult and expensive to collect hydro-climatic information at micro level. The use of satellite imagery from metrological satellite and earth observation satellites will be best way to understand the changing climatic scenarios at regional and local scale. It is now possible to receive near real time meteorological data of any part of the world. Use of the remote sensing techniques to analyze satellite imagery will be the best way to generate hydro-climatic data at small watershed scale. Based on spatial analysis we can present station-based hydro-climatic datainto small watershed units and predict spatial variability. Using geospatial technology can integrate and handle the hydro-climatic data and perform predictive modeling to understand the uncertainty of impact of climate change in hydropower development.

Dearth of hydro-climatic data is also crucial factor in dealing with uncertainty in hydropower development. In the lastfew years a great deal of effort has been made by various agencies to explore hydropower potentiality and possibilities. A number of individual studies have been conducted at various stations in different major and tributaries rivers. It is now time to integrate all the observations to fill the spatial and temporal gaps in hydroclimatic data. There is need to design a hydro-climatic data facility to integrate the scattered and isolated information. It is necessary to design a scientific model to manage ground based observations and near real time metrological data to predict variability, to understand the uncertainty of climate change for hydropower development in Nepal.

\section{Conclusion}

It is obvious that water resources and hydropower are vulnerable areas of uncertainty in climate change scenarios and that understanding regional and local variability is crucial for hydropower development. Development of scientific and near real time hydro-climatic data is the urgent need to mitigate the uncertainty of climate change for hydropower development in Nepal.

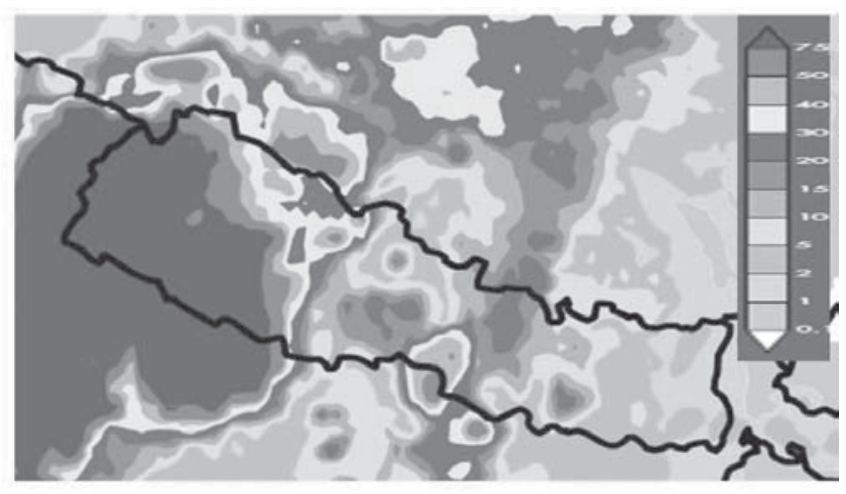

Figure 4. Estimation of Rainfall Using Satellite Imagery (Shrestha et al 2008).
Mahesh Pathak has expertise in GIS and remote sensing applications for land use and land cover mapping, river morphology and watershed management. He holds a masters' degree in Geography in Tribhuvan University, in which he was awarded a gold Medal. He has also received and SCGIS Global Scholarship Award 2007 and took advanced GIStraining on conservation and water resource management from ESRI (Environemnt Sensitivities Research Institute), in the USA.

Corresponding Address: pathakmsh@gmail.com

\section{References}

Agrawala, Shardul, V. Raksakulthai, M. van Aalst, P. Larsen, J. Smith and J. Reynolds, 2003, Development and Climate Change in Nepal: Focus on Water Resources and Hydropower, Paris: Organization for Economic Co-operation and Development (OECD); URL: http://calclimate.berkeley.edu/sites/default/files/ OECD_Nepal_Hydropower_2003.pdf.

McCarthy, J ames J ., O.F. Canziani, N.A. Leary, D.J. Dokken and K.S.White, editors, 2001, Climate Change 2001: Impacts, Adaptation, and Vulnerability, Contribution of Working Group II to the Third Assessment Report of the Intergovernmental Panel on Climate Change.

Mool, P.K., S.R. Bajracharya and S.P.J oshi, 2002, Inventory of Glaciers, Glacial Lakes and Glacial Lake Outburst Floods Monitoring and Early Warning Systems in the HindukushHimalayan Region: Nepal, Kathmandu: International Center for Integrated Mountain Development (ICIMOD).

Pathak, Mahesh, 2008, 'Application of GIS and Remote Sensing for Hydropower Development in Nepal', Hydro Nepal: J ournal of Water, Energy and Environment v.3.

Shakya, N.M., 2003, 'Hydrological changes assessment and its impact on hydro power projects of Nepal', in Proceedings of the Consultative Workshop on Climate Change Impacts and Adaptation Options in Nepal's Hydropower Sector with a Focus on Hydrological Regime Changes Including GLOF, Department of Hydrology and Meteorology and Asian Disaster Preparedness Center, 5-6 March 2003, Kathmandu.

Shrestha M., S.R. Bajracharya and P. Mool, 2008, Satellite Rainfall Estimation in the Hindu Kush-Himalayan Region, Kathmandu: International Center for Integrated Mountain Development (ICIMOD).

Shrestha, Arun B., C.P. Wake, P.A. Mayewski and J.E. Dibb, 1999, 'Maximum temperature trends in the Himalaya and its vicinity: An analysis based on temperature records from Nepal for the period 1971- 94', J ournal of Climate v.12, n.9, pp.27752786; URL: http:// ams.allenpress.com/ perlserv/ ?request=getabstract\&doi $=10$.1175/ 1520 - 0442 (1999) $012<2775$ : MTTITH $>2.0 . C O ; 2 \& c t=1$

Subbiah, 2001, ClimateVariabilityandDroughtin Southwest Asia, Bangkok: Asian Disaster Preparedness Center.

Thomas K. J . and S.C. Rai, 2005, An Overview of Glaciers, Glacier Retreat, and Subsequent Impacts in Nepal, India and China, Kathmandu, World Wildlife Fund Nepal. • 